\title{
Analisis Hubungan BBLR (Berat Bayi Lahir Rendah) dan Asfiksia dengan Ikterus Neonatorum
}

\section{Relationship Analysis of LBW (Low Birth Weight) and Asphyxia with Neonatory Jicterus}

\author{
Eka Frelestanty ${ }^{1 *}$, Lea Masan ${ }^{1}$ \\ ${ }^{1}$ Prodi DIII Kebidanan STIKes Kapuas Raya Sintang, Kalimantan Barat, Indonesia \\ *Korespondensi penulis: eka.frelestanty@yahoo.com
}

Penyerahan: 25-08-2020, Perbaikan: 09-09-2020, Diterima: 16-09-2020

\begin{abstract}
The cause of neonatal jaundice is still a predisposing factor. Besides, risk factors for hyper-bilirubin include preterm infants or gestational age $<37$ weeks, babies with low birth weight (LBW), and the type of delivery. This study aims to determine the relationship between LBW and asphyxia with neonatal jaundice. The research was conducted by using quantitative descriptive research through a retrospective approach. The sampling technique used total sampling, namely all the newborns at the Ade Muhammad Djoen Sintang Regional Hospital in 2019, was 265 babies. The results of the test using Chi-square gave $\mathrm{p}$-value $<0.001$, meaning that there was a relationship between LBW and asdixia with neonatal jaundice.
\end{abstract}

Keywords: LBW, Asphyxia, neonatal jaundice

\section{ABSTRAK}

Penyebab ikterus neonatorum masih merupakan faktor predisposisi. Disamping itu, faktor risiko terjadinya hiperbillirubin diantaranya bayi kurang bulan atau kehamilan usia $<37$ minggu, bayi dengan berat lahir rendah (BBLR) dan jenis persalinan. Penelitian ini bertujuan untuk diketahuinya hubungan BBLR dan asfiksia dengan ikterus neonatorum. Penelitian dilakukan dengan jenis penelitian deskriptif kuantitatif melalui pendekatan retrospektif. Teknik pengambilan sampel menggunakan total sampling, yaitu seluruh bayi baru lahir di RSUD Ade Muhammad Djoen Sintang tahun 2019 sebanyak 265 bayi. Hasil pengujian menggunakan Chi square memberikan hasil p-value $<0.001$ artinya ada hubungan antara antara BBLR dan asdiksia dengan ikterus neonatorum.

Kata kunci: BBLR, Asfiksia, ikterus neonatorum

\section{PENDAHULUAN}

Penyebab ikterus neonatorum masih merupakan faktor predisposisi. sering ditemukan antara lain faktor maternal seperti komplikasi kehamilan (inkontabilitas golongan darah $A B O$ dan $R h$ ), dan pemberian air susu ibu (ASI), faktor perinatal seperti infeksi, dan trauma lahir (cephalhematom), dan faktor neonatus seperti prematuritas, rendahnya asupan ASI, hipoglikemia, dan faktor genetik . disamping itu, faktor risiko terjadinya hiperbillirubin diantaranya bayi kurang bulan atau kehamilan usia <37 minggu, bayi 
dengan berat lahir rendah (BBLR) dan jenis persalinan (Faiqah, 2013).. Menurut WHO diperkirakan sekitar 900.000 kematian bayi baru lahir setiap tahun diakibatkan oleh asfiksia neonatorum. Laporan dari Organisasi Kesehatan Dunia WHO menyebutkan bahwa sejak tahun 2000-2003 asfiksia menempati urutan ke-6, yaitu sebanyak $8 \%$ sebagai penyebab kematian neonatal diseluruh dunia setelah pneumonia, malaria, sepsis neonatorum, dan kelahiran prematur (Zainuddin, 2012).

Angka Kematian Bayi (AKB) di Indonesia terus menurun setiap tahun. Namun, jalan memerangi AKB masih panjang. Hasil Survei Demografi dan Kesehatan Indonesia (SDKI) menunjukkan dari tahun ke tahun AKB mengalami penurunan signifikan. Dari 68 kematian per 1.000 kelahiran hidup pada 1991, hingga 24 kematian per 1.000 kelahiran hidup pada tahun 2017. AKB sebagian besar disebabkan oleh asfiksia (20-60\%), infeksi (25-30\%), bayi dengan berat lahir rendah (25$30 \%$ ), dan ikterus (30-40\%) (SDKI, 2017). Asfiksia adalah keadaan dimana bayi yang baru dilahirkan tidak segera bernafas secara spontan dan teratur setelah dilahirkan. Hal ini disebabkan oleh hipoksia janin dalam rahim yang berhubungan dengan faktor-faktor yang timbul dalam kehamilan, persalinan dan setelah kelahiran. Menurut Towell (1996 dikutip dari Ilyas, Mulyati \& Nurlina 2012).

Hasil studi pendahuluan di RSUD Ade Mohammad Djoen Kabupaten Sintang pada minggu kedua bulan April 2020 dengan mempelajari data rekam medis menunjukkan jumlah bayi baru lahir selama tahun 2019 adalah 265bayi. Jumlah bayi yang lahir dengan asfiksia adalah 32 bayi. sedangkan bayi dengan BBLR sejumlah 48 dan bayi yang mengalami BBLR dan asfiksia sejumlah 80 bayi. Berdasarkan latar belakang diatas, menunjukan bahwa angka kejadian bayi BBLR dan asfiksia masih tinggi. Kejadian Ikterus neonatorum di Rumah Sakit Umum Daerah Ade Mohammad Djoen Sintang tahun 2017 berjumlah 26 kasus di tahun 2018 berjumlah 38 kasus sedangkan di tahun 2019 berjumlah 54 kasus. Terjadi kenaikan setiap tahunnya. Berdasarkan latar belakang di atas peneliti merasa perlu melakukan penelitian analisis hubungan BBLR dan Asfiksia dengan ikterus neonatorum di Rumah Sakit Umum Daerah Ade Mohammad Djoen Sintang Tahun 2020. Mengetahui analisis hubungan BBLR dan asfiksia dengan ikterus neonatorum di RSUD Ade Muhammad Djoen Kabupaten Sintang Tahun 2020. Angka kematian bayi di Kalimantan Barat masih sangat memprihatinkan. Salah satu indikator derajat kesehtaan masyarakat Proporsi terbesar dari angka kemaian bayi terjadi pada masa neonatal. Angka Kematian Bayi (AKB) di Kalimantan Barat sebanyak 558 kaus per 100.000 kelahiran hidup kabupaten sintang menempati peringkat pertama dengan 95 kasus. Kematian bayi terbanyak disebabkan oleh asfiksia 35,9\%, BBLR 35,5\%, prematur $34,49 \%$, sepsis $12,1 \%$, hipotermi 6,35\%, ikterus 5,6\%, postterm 2,8\% dan kelaina kongenital 1,4\%, (Profil Kaimantan Barat).

Asfiksia adalah kegagalan untuk memulai dan melanjutkan pernafasan secara spontan dan teratur pada saat bayi baru lahir atau beberapa saat sesudah lahir. Bayi mungkin lahir dalam kondisi asfiksia (Asfiksia Primer) atau mungkin dapat bernafas tetapi kemudian mengalami asfiksia 
beberapa saat setelah lahir (Asfiksia Sekunder) ( Icesmi \& Sudarti, 2014). Tujuan penellitian ini adalah Mengetahui Aanalisis hubungan BBLR dan Asfiksia dengan ikterus neonatorum di Rumah Sakit Umum Ade Mohamad Djoen Sintang Tahun 2020.

\section{METODE}

Desain pada penelitian ini menggunakan desain penelitian deskriptif kuantitatif dengan pendekatan retrospektif. Penelitian deskriptif adalah suatu metode penelitian yang dilakukan dengan tujuan utama membuat gambaran atau deskriptif suatu keadaan atau area populasi tertentu yang bersifat faktual secara objektif. Pendekatan kuantitatif adalah data yang berhubungan dengan angka-angka yang diperoleh dari hasil pengukuran (Notoatmodjo, 2010). Pendekatan studi retrospektif yaitu jika meneliti peristiwa kebelakang menggunakan data sekunder (Chandra, 2008). Teknik pengambilan sampel dengan teknik total sampling. Total Sampling adalah teknik penentuan sampel bila semua anggota populasi digunakan sebagai sampel (Sugiyono, 2011). Sampel dalam penelitian ini adalah seluruh anggota populasi yaitu 486 ibu bersalin di Rumah Sakit Umum Daerah Ade Muhammad Djoen Kabupaten Sintang Tahun 2018. Analisis data yang digunakan dalam penelitian ini adalah Univariat dan Bivariat.

\section{HASIL}

Tabel 1. Distribusi Karakteristik Responden

\begin{tabular}{lcc}
\hline \multicolumn{1}{c}{ Variabel } & Jumlah & Persentase \\
\hline BBLR & & \\
$<2500$ gram & 49 & 18.5 \\
$\geq 2500$ gram & 216 & 81.5 \\
Asfiksia neonatorum & & \\
Ya & 32 & 12.1 \\
Tidak & 233 & 87.9 \\
Ikterus neonatorum & & \\
Ya & 54 & 20.3 \\
Tidak & 211 & 79.6 \\
\hline
\end{tabular}

Tabel 2. Hubungan asfiksia dan BBLR dengan ikterus neonatorum

\begin{tabular}{lccc}
\hline \multicolumn{1}{c}{ Variabel } & \multicolumn{2}{c}{ Ikterus } & P-value \\
\cline { 2 - 3 } & Ya & Tidak & \\
\hline BBLR & & $21(9.7 \%)$ & $<0.001$ \\
$\geq 2500$ gram & $195(90.3 \%)$ & $33(67.3 \%)$ & \\
$<2500$ gram & $16(32.7 \%)$ & & \\
Asfiksia & & $22(9.4 \%)$ & $<0.001$ \\
Ya & $211(90.6 \% \%)$ & $\mathbf{3 2}(\mathbf{1 0 0 \% )})$ & \\
Tidak & 0 &
\end{tabular}

Berdasarkan tabel 1 dari 265 responden dapat dilihat sebagian besar bayi lahir dengan berat lebih dari 2500 gram, sedangkan sebagian kecil bayi berat lahir rendah atau berat lahir $<2500$ gram sebanyak 49 bayi $(18.5 \%)$. Hampir seluruh bayi baru lahir tidak mengalami asfiksia dengan frekuensi sebesar 233 bayi (87.9\%), dan sangat sedikit bayi mengalami asfiksia dengan frekuensi 32 bayi (12.1\%). Sebagian besar 
bayi baru lahir tidak mengalami ikterus neonatorum dengan frekuensi sebesar 211 bayi (79.6\%), dan sebagian kecil bayi mengalami ikterus neonatorum dengan frekuensi 54 bayi (20.3\%).

Hasil pengujian menggunakan Chi square memberikan hasil $p$-value $<0.001$. Ha diterima dan Ho ditolak yang artinya ada hubungan antara BBLR dengan ikterus neonatorum. Hasil pengujian menggunakan Chi square memberikan hasil $p$-value $<0.001$. Ha diterima dan Ho ditolak yang artinya ada hubungan antara asfiksia dengan ikterus neonatorum.

\section{PEMBAHASAN}

Berdasarkan tabel 1 dari 265 responden dapat dilihat sebagian besar bayi lahir dengan berat lebih dari 2500 gram, sedangkan sebagian kecil bayi berat lahir rendah atau berat lahir <2500 gram sebanyak 49 bayi $(18,5 \%)$. dari 265 responden yang diteliti didapatkan hasil sebagian besar bayi baru lahir tidak mengalami ikterus neonatorum dengan frekuensi sebesar 211 bayi $(79,6 \%)$, dan sebagian kecil bayi mengalami ikterus neonatorum dengan frekuensi 54 bayi $(20,4 \%)$. Hasil pengujian menggunakan Chi square memberikan hasil pvalue $=0,00 \leq 0,05$. Ha diterima dan $\mathrm{Ho}$ ditolak yang artinya ada hubungan antara antara BBLR dengan ikterus neonatorum. Hasil penelitian ini mendukung teori dari Proverawati dan Ismawati (2010) yaitu pada berat badan lahir rendah dapat mengalami risiko jangka pendek, diantaranya adalah asfiksia. Bayi dengan berat badan lahir rendah baik yang kurang, cukup atau lebih bulan dapat mengalami gangguan pada proses adaptasi pernafasan waktu lahir sehingga dapat mengalami ikterus neonatorum. Bayi berat lahir rendah (BBLR) ialah bayi baru lahir yang berat badannya saat lahir kurang dari 2500 gram (sampai dengan 2499 gram). Beberapa penyakit yang berhubungan dengan prematuritas : sindrom gangguan pernafasan idiopatik (penyakit membrane hialin), pneumonia aspirasi karena reflex menelan dan batuk belum sempurna, perdarahan spontan dalam ventrikel otak lateral, akibat anoksia otak (erat kaitannya dengan gangguan pernafasan), ikterus karena fungsi hati belum matang dan hipotermia (Wiknjosastro, 2014). Menurut asumsi peneliti banyaknya kejadian ikterus yang disebabkan oleh BBLR yaitu 19 bayi (35\%). BBLR erat kaitannya dengan kelahiran bayi premature, sehingga terjadinya ikterus pada BBLR disebabkan karena belum matangnya fungsi hati (Yuliastutik, 2016).

Berdasarkan hasil penelitian, Analisis Hubungan asfiksia dengan ikterus neonatorum di Rumah Sakit Umum Daerah Ade Muhammad Djoen Kabupaten Sintang tahun 2020.

Berdasarkan tabel 2 dari 265 responden yang diteliti didapatkan hasil hampir seluruh bayi baru lahir tidak mengalami asfiksia dengan frekuensi sebesar 233 bayi (87,9 \%), dan sangat sedikit bayi mengalami asfiksia dengan frekuensi 32 bayi $(12,1 \%)$. dari 265 responden yang diteliti didapatkan hasil sebagian besar bayi baru lahir tidak mengalami ikterus neonatorum dengan frekuensi sebesar 211 bayi $(79,6 \%)$, dan sebagian kecil bayi mengalami ikterus neonatorum dengan frekuensi 54 bayi $(20,4 \%)$. Hasil pengujian menggunakan Chi square memberikan hasil pvalue $=0,00 \leq 0,05$. Ha diterima dan $\mathrm{Ho}$ ditolak yang artinya ada hubungan antara antara asfiksia dengan ikterus neonatorum. Hasil penelitian ini tidak sama dengan hasil penelitian sebelumnya yang 
dilakukan oleh Siti Faridah tahun 2018 dengan judul Gambaran Ikterus Neonatorum Patologis Pada Bayi Aterm Hasil penelitian didapatkan bahwa tidak satupun ikterus neonatorum patologis disebabkan oleh faktor ibu, dan seluruhnya disebabkan oleh faktor bayi. Faktor bayi sebagian besar $(54,31 \%)$ karena hipoksia. Sedangkan yang lainnya disebabkan karena 19,83 infeksi; 19,5 trauma lahir; 3,45 penurunan peristaltik usus; dan 2,58\% asfiksia. Hasil penelitian sesuai dengan hasil penelitian sebelumnya di karnakan Asfiksia Neonatorum merupakan sesuatu keadaan pada bayi baru lahir yang mengalami gagal bernapas secara sepontan dan teratur segera memasukan oksigen dan tidak dapat mengeluarkan zat asam arang dari tubuhnya (Dewi, 2011). Hal ini sejalan dengan teori, ikterus terjadi pada bayi asfiksia karna fungsi hiper belum matang atau terdapat gangguan pernapasan seperti hipoksia.

Asfiksia adalah keadaan dimana bayi baru lahir tidak dapat bernapas secara spontan dan teratur. Bayi dengan riwayat gawat janin sebelum lahir, umumnya akan mengalami asfiksia pada saat dilahirkan. Masalah ini erat hubungannya dengan gangguan kesehatan ibu hamil, kelainan tali pusat, atau masalah yang mempengaruhi kesejahteraan bayi selama atau sesudah persalinan (Asuhan Persalinan Normal, 2014). Menurut asumsi penelitian 10 (19\%) bayi yang mengalami ikterus yang disebabkan oleh asfiksia berkaitan dengan gangguan pernafasan dimana bayi baru lahir tidak bernafas sepontan di karnakan kurangnya oksigen masuk ke dalam tubuh bayi, sehingga bayi tidak bisa bernafas spontan.

\section{KESIMPULAN}

Diketahui dari 265 responden sebagian besar bayi lahir dengan berat lebih dari 2500 gram, dan sebagian besar bayi baru lahir tidak mengalami ikterus neonatorum dengan frekuensi sebesar 211 bayi $(79,6 \%)$. Hasil pengujian menggunakan Chi square memberikan hasil ada hubungan antara antara BBLR dengan ikterus neonatorum dan ada hubungan antara antara asfiksia dengan ikterus neonatorum.

\section{SARAN}

Setelah dilakukan penelitian terhadap 265 bayi baru lahir mengenai "analisis Rumah Sakit Disarankan agar lebih meningkatkan penanganan pada kejadian ikterus neonatorum pada bayi baru lahir serta diharapkan pemeriksaan golongan darah pada bayi dapat dilakukan 1 hari setelah kelahiran atau sebelum bayi pulang agar kelainan pada bayi seperti ikterus neonatorum dapat terdeteksi sedini mungkin.

\section{UCAPAN TERIMA KASIH}

Peneliti mengucapkan terima kasih kepada Prodi DIII Kebidanan STIKes Kapuas Raya Sintang, atas izin yang diberikan untuk lancarkan penelitian ini.

\section{DAFTAR PUSTAKA}

Anggraini, Y. (2016). Hubungan Antara Persalinan Prematur Dengan Hiperbilirubin Pada Neonatus. Jurnal kesehatan, 5(2). Tersedia : ejurnal.poltekkestjk.ac.id (Diakses tanggal 03 April 2020)

Arikunto, S. (2013). Prosedur Penelitian Suatu Tidakan Praktik.

Arikunto, S. (2010). Prosedur Penelitian Suatu Pendekatan 
Praktik. 2010. Jakarta: Rineka Cipta.

Statistik, B. P. (2016). Kalimantan Barat Dalam Angka 2005-2006. Tersedia

https://kalbar.bps.go.id/ (Diakses tanggal 01 April 2020)

Depkes, R. I. (2018). Data dan Informasi Profil Kesehatan Indonesia. Jakarta: Pusat Data dan Informasi Ke-menterian Kesehatan Republik Indonesia.Tersedia www.depkes.go.id tanggal 01 April 2020)

(Diakses

Faiqah, S. (2018). Hubungan Usia Gestasi dan Jenis Persalinan Dengan Kadar Bilirubinemia Pada Bayi Ikterus di RSUP NTB. Jurnal Kesehatan Prima, 8(2), 13551362. Tersedia : poltekkesmataram.ac.id (Diakses tanggal 03 April 2020)

Maryunani, A. 2016. Asuhan Neonatus, Bayi, Balita \& Anak Pra Sekolah. Bogor : IN MEDIA

Mutianingsih, R. (2014). Hubungan antara bayi berat lahir rendah dengan kejadian ikterus, hipoglikemi dan infeksi neonatorum di RSUP NTB tahun 2012. Universitas Brawijaya Malang. Tersedia

www.ws.ub.ac.id (Diakses tanggal 03 April 2020)

Notoatmodjo, S. (2010). Metodologi penelitian kesehatan.

Notoatmodjo, S. (2011). Kesehatan masyarakat. Jakarta: Rineka Cipta.

Mauliku, N. E., \& Nurjanah, A. (2017). Faktor-Faktor Pada Ibu Bersalin Yang Berhubungan Dengan Kejadian Hiperbillirubin Pada Bayi Baru Lahir Di Rumah Sakit Dustira Cimahi Tahun 2009. Jurnal Kesehatan Kartika. Tersedia : www.stikesayani.ac.id (Diakses tanggal 03 April 2020)
Rukiyah, A.I dan Lia Y. 2013. Asuhan Neonatus Bayi dan Anak Balita. Jakarta : Trans Info Media

Saputra, R. G. (2016). Perbedaan Kejadian Ikterus Neonatorum antara Bayi Prematur dan Bayi Cukup Bulan pada Bayi dengan Berat Lahir Rendah di RS PKU Muhammadiyah Surakarta (Doctoral dissertation, Universitas Muhammadiyah Surakarta). Tersedia : www.eprints.ums.ac.id (Diakses tanggal 01 April 2018)

Survey Demografi Kesehatan Indonesia. 2012. Tersedia : www.depkes.go.id (Diakses tanggal 01 April 2020)

Umi, N. 2018. Metodologi Penelitian Kualitatif dan Kuantitatif. Teori dan Aplikasi. Bandung : Agung Media

Wiknjosastro, H. (2014). IImu kebidanan. Jakarta : Yayasan Bina Pustaka Sarwono Prawirohardjo 